\title{
MORPHODYNAMIC OF BEACH SCARPS ON A MACROTIDAL COAST DURING EXCEPTIONAL WATER LEVEL EVENTS (NORMANDY, FRANCE)
}

Yoann Bonte ${ }^{1}$ \& Franck Levoy ${ }^{2}$

1 - PhD student (yoann.bonte@unicaen.fr) / 2 - Professor, PhD director (franck.levoy@unicaen.fr)

University of Caen Basse-Normandie, M2C laboratory, UMR CNRS 6143

\section{INTRODUCTION}

Numerous studies on the morphology and physical processes affecting the dune's scarp and many conceptual models describing beach scarps on microtidal and mesotidal environments exist Sunamura, 1985 ; Short, 1999), but really quantitative information about beach scarp is lacking, especially along tidal environments where the tide controls the level of wave attack (macrotidal coast). Sherman and Nordstrom (1985) give a qualitative description of beach scarp formations and evolution based on field observations but without data set.

The aim of this study is to add quantitative information about the evolution of a berm scarp during erosive hydrodynamic conditions.
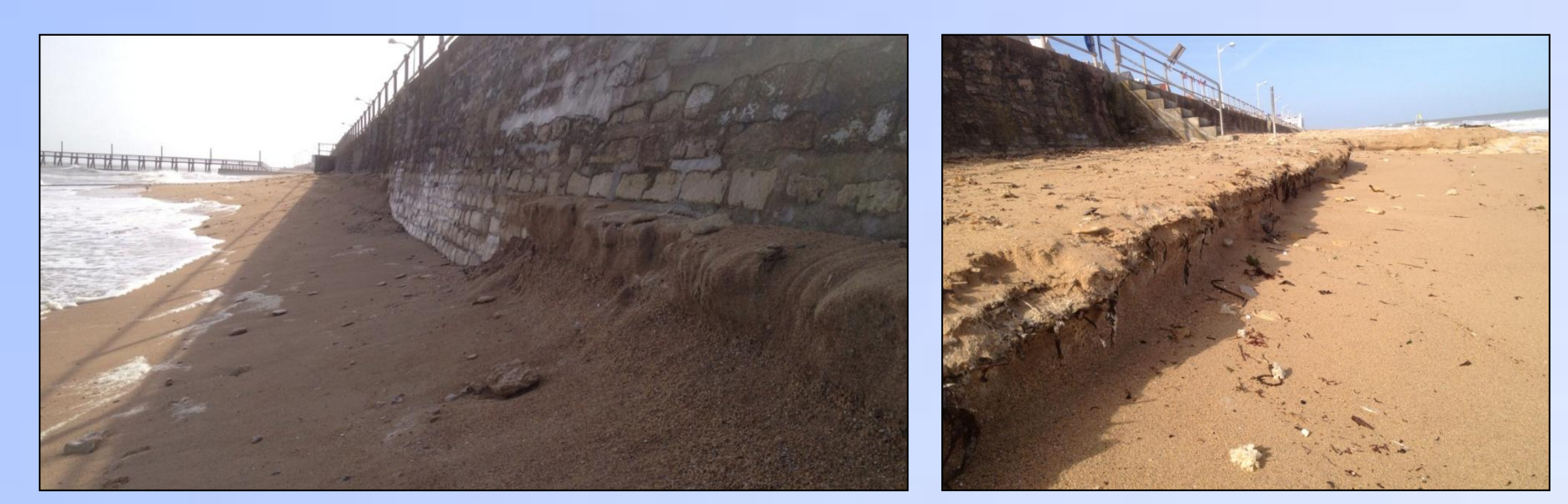

\section{FIELD EXPERIMENT}

A 35 metres long and 1 metre high artificial berm with a scarp is constructed and compacted using a bulldozer on the high tidal zone of Luc-sur-Mer (Normandy, France), to study its destruction during a stormy spring tide event.

Many instruments are deployed during this campaign with the aim of measuring the scarp evolution (longshore and cross-shore) during high tides.

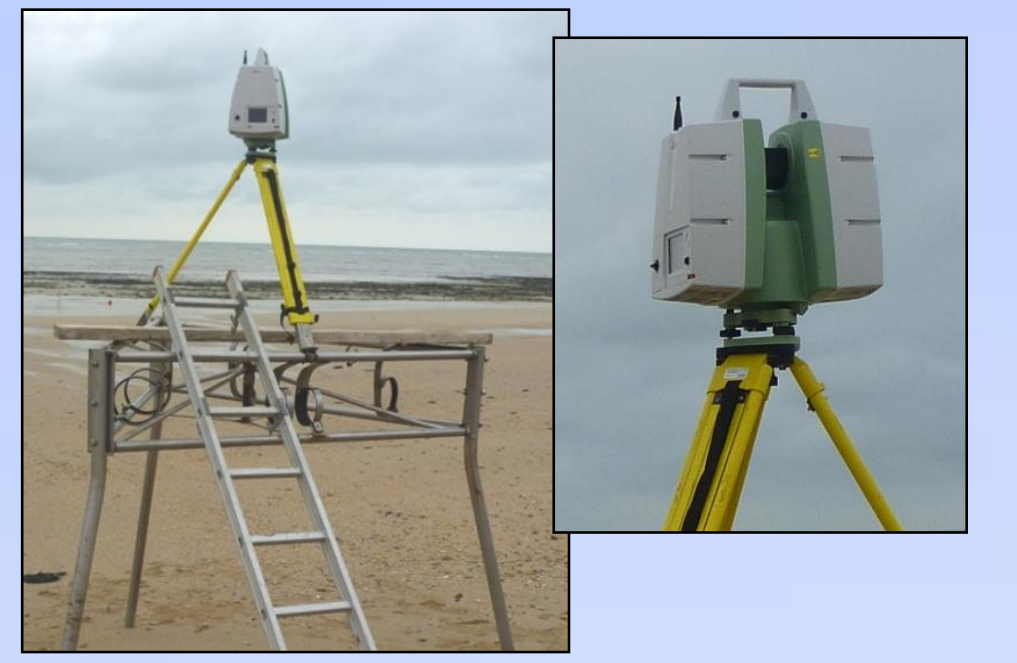

\section{TOPOGRAPHY}

Topographic surveys is done with a DGPS and a terrestrial scanner laser (Leica C10) at each low tide on the study area, and at every beginning and ending of high tide video acquisition on the beach scarp.

VIDEO

Two video cameras placed on a 6 metres mast top on the beach record images of the beach scarp at a frequency of $1.87 \mathrm{~Hz}$ during a burst period of 20 minutes every 30 minutes. Images permit to analyse the swash action in front of the scarp (impact numbers, submersion...).

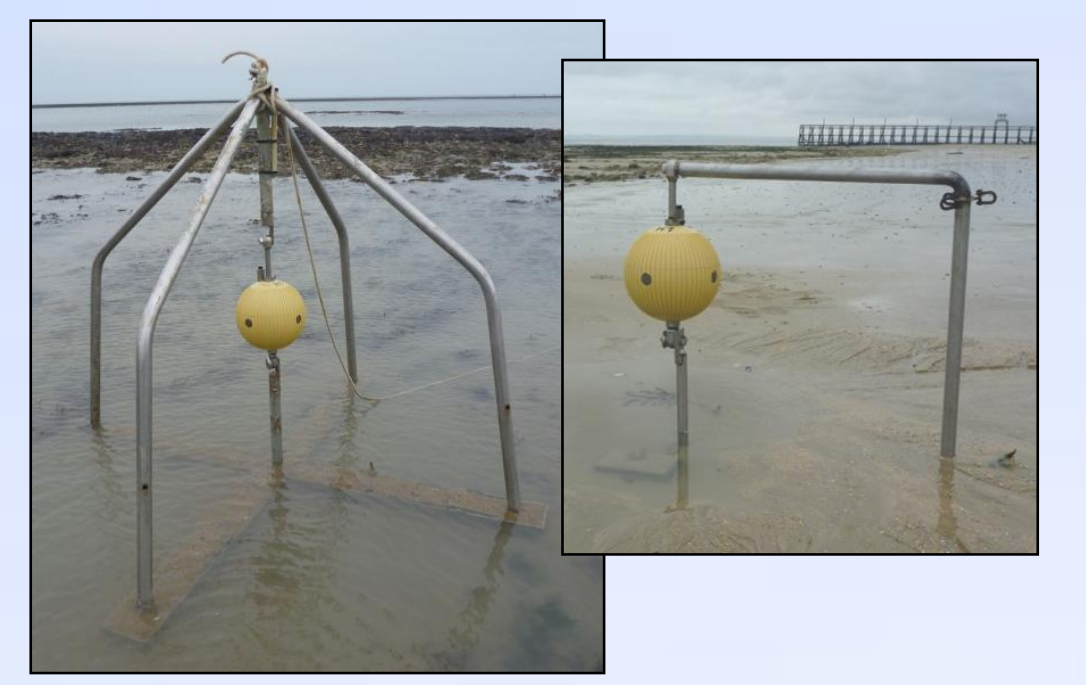

\section{HYDRODYNAMIC}

Two electromagnetic currentmeters fitted with pressure sensors (InterOcean S4 DW) located on the mid and lower foreshores record continuously waves, current and water level at a $2 \mathrm{~Hz}$ frequency.

\section{RESULTS I}

We examine the morphological response of an artificial beach scarp to different hydrodynamic conditions during many tides. The two more erosive tides in 2011 and 2012 are described below.

\section{HYDRODYNAMIC}

The hydrodynamic settings are stormy with onshore wind in 2011 and side shore wind in 2012 that generate different conditions during these two experimentations (Table 1).

In 2011, waves are bigger (height and period) than in 2012 but with an incoming wave angle from shore normal less important. On the other hand, the observed max water level is higher than predicted in 2012, and similar in 2011, due to atmospheric pressure.

\section{MORPHOLOGY}

The different hydrodynamic conditions during the experiments of 2011 and 2012 induce contrasted erosions of the beach scarp.

During the 2011 campaign, the scarp is regularly retreated landward after every tide. The figure $1 \mathrm{~A}$ highlights a regular cross-shore erosion.

The sediments eroded from the scarp by the swash impact on the foot scarp are mainly transported seaward. A new bar is observed on the mid-foreshore. The scarp is maintained.

During the 2012 campaign, the scarp is totally destroyed during one tide. The figure $1 \mathrm{~B}$ shows a contrasted longshore topographic evolution. On the west part, the beach is eroded and on the east area, the ediments are deposited. It induced a scarp height decreasing from the West to the East part of the scarp

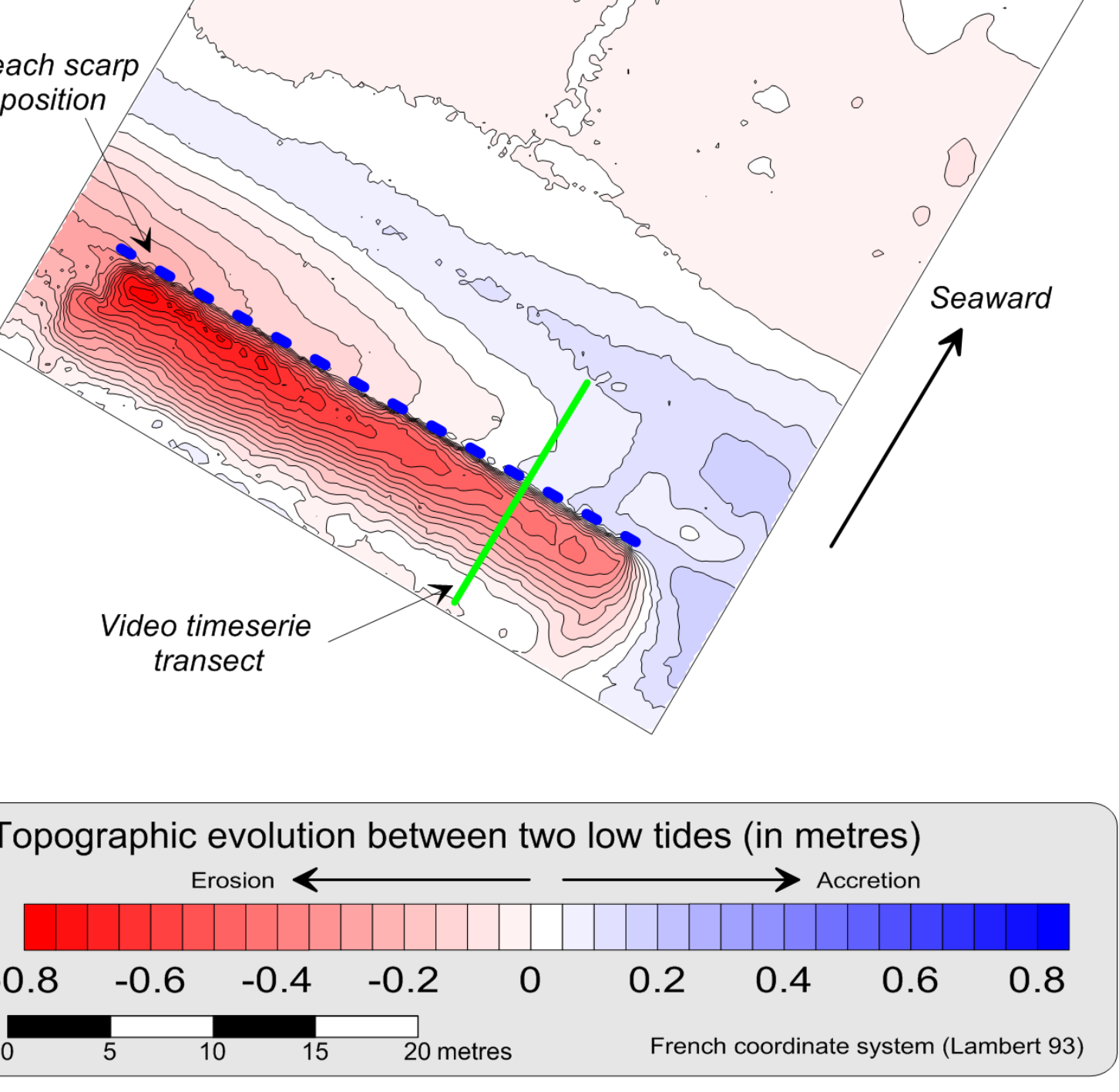

$\bigwedge^{N} \quad \begin{aligned} & \text { Figures } 1-\text { Topographic } \\ & \text { evolution of the artificial } \\ & \text { boach }\end{aligned}$ beach scarp during one
tide in 2011 (A) and in $2012(B)$

$$
\text { 6918430- }
$$

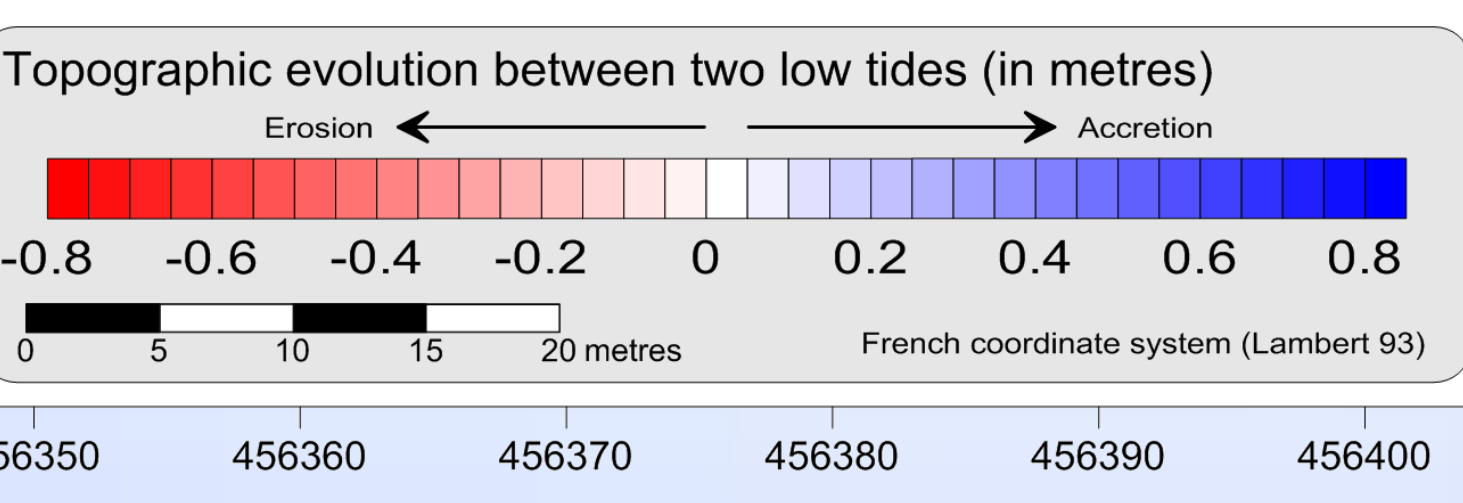

\section{RESULTS I}

During the 2012 fieldwork, topographical recording of the beach scarp with a terrestrial scanner laser are done at high tide together with video measurements during the principal erosion tide of the experimentation.

Video time series and topographical data are extracted on a similar cross shore transect (Figure $1 \mathrm{~B}$ ). Video time series are digitized and the number of impacts on scarp is extracted. High tide topographical acquisitions permit to know the eroded volume from the scarp in time and correlate it with the number of swash impacts, the water level and the waves conditions.

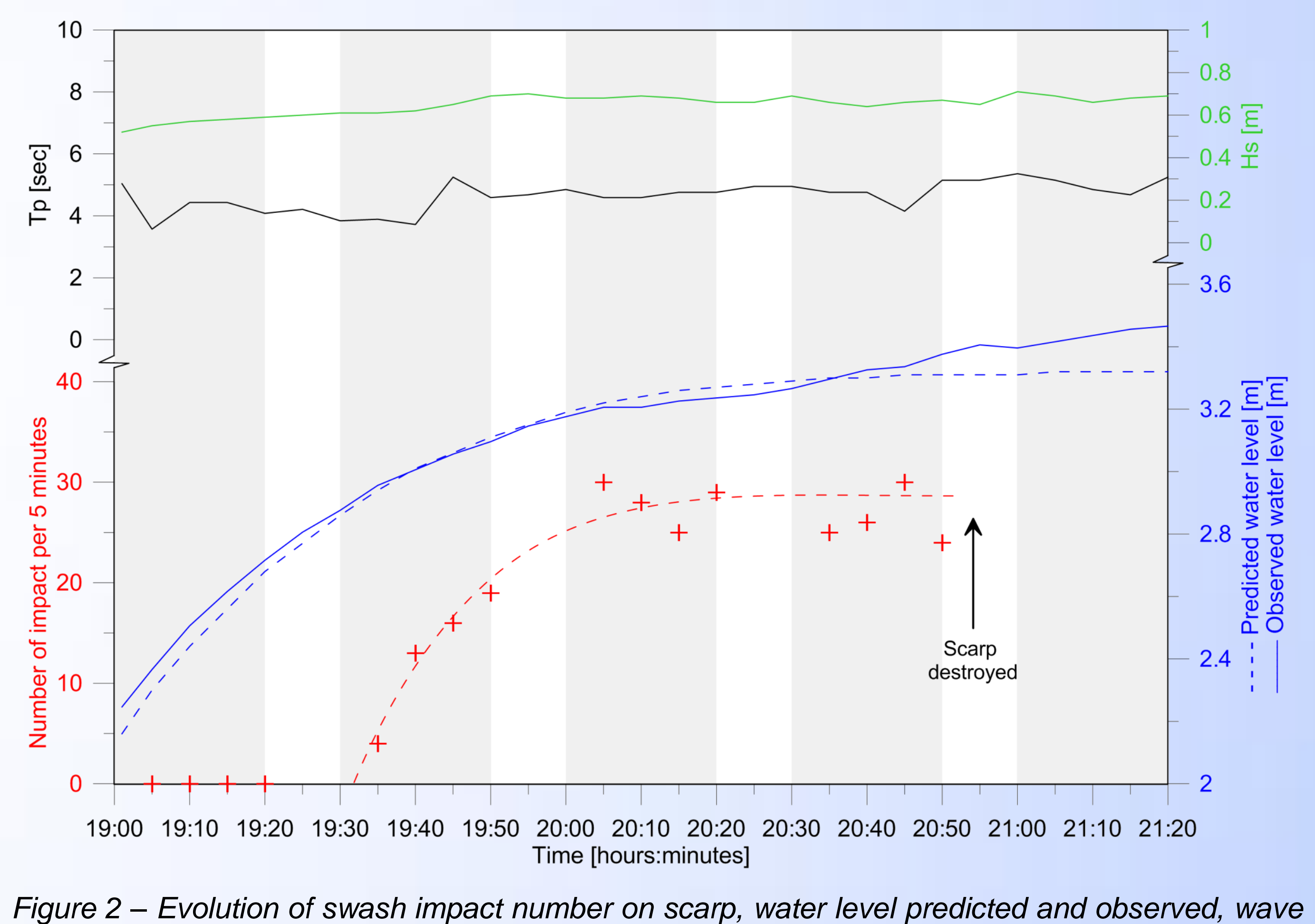

Figure 2 - Evolution of swash impact number on scarp, water level predicted and observed, wave
height and period during the eroding tide in 2012 (gray patch correspond to video acquisition).

The figure 2 shows that the number of impacts tends to become constant at a certain time when the water level is still increasing and the wave height and period are not significantly changing. In the same time the foot scarp migrates up and landward.

The relation between impact number and the eroded volume is not constant due to the force of the impact which is an important setting that has to be taken into account (Figure 3).

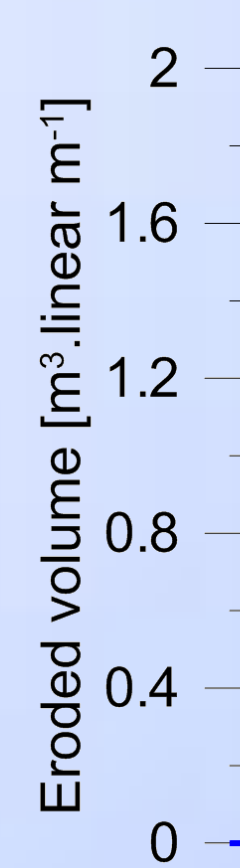

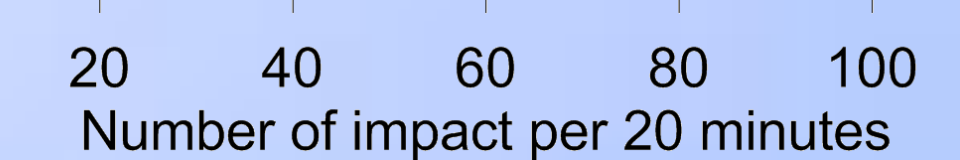
Figure 3 - Eroded volume from the scarp
vs. swash impact number
Despite lower hydrodynamic conditions (wave height and period) during the 2012 vs. 2011 experimentation, the beach scarp is totally destroyed.

The high tide water level observed during the 2012 campaign seems to mainly control the beach scarp erosion, but the contrasted beach evolution provokes a differential erosion along the scarp.

\section{CONCLUSION}

The tide level controls the evolution of the scarp foot and milder wave conditions may be much more erosive when acting with a higher water level.

The wave angle from shore normal is also important for beach scarp evolution. The induced longshore transport modifies the topography on the swash zone and facilitates the impacts of swash on scarp head where the beach is eroded, but contributes to its stabilization where the beach is accreted. Then erosion of the scarp must be accelerated or stopped depending on the location of measurements.

Eroded volume on the beach scarp is linked to the number of impacts but the force of each impact on the scarp must be considered.

The relationships between hydrodynamic conditions, scarp and beach evolutions must be deeply analyzed using all recorded data. 